\title{
A EVOLUÇÃO DA SUSTENTABILIDADE AMBIENTAL URBANA E AS INTERFERÊNCIAS DA ÉTICA
}

\author{
Deize Sbarai Sanches Ximenes \\ Mestre em Arquitetura e Urbanismo - PósArq da UFSC - Brasil \\ E-mail :sanchesarquiteta@uol.com.br
}

\begin{abstract}
Resumo
A intenção deste artigo é apresentar as influências da ética na evolução da sustentabilidade ambiental a partir do séc. XIX quando ocorre um rápido desenvolvimento das cidades e um crescimento desordenado da população gerando problemas sociais e ambientais. O ambiente natural sofreu, por muito tempo, com a atividade predatória do ser humano, que estimulado por sua ganância, retirou de forma irresponsável e sem planejamento, as riquezas naturais em busca de lucro comprometendo a sobrevivência sustentável. A visão tradicional antropocêntrica enfatiza um desenvolvimento ambiental urbano focado nos interesses e bem estar do ser humano desde a existência do homem, enquanto a biocêntrica, desloca o eixo da ética para os seres vivos e os ecossistemas naturais, onde teremos a introdução à ética ambiental na década de 70 e o conceito de ecodesenvolvimento.
\end{abstract}

Palavras-chave: evolução, sustentabilidade ambiental urbana, ética antropocêntrica, ética biocêntrica, ecodesenvolvimento. 


\title{
THE EVOLUTION OF THE URBAN ENVIRONMENTAL SUSTAINABILITY AND THE ETHICS INTERFERENCES
}

\begin{abstract}
The intention of this article is to present the influence of ethics in the evolution of environmental sustainability from the century XIX when there is rapid development of cities and a disorderly growth of the population generating social and environmental problems. The natural environment has suffered for a long time, with the predatory activity of human beings, that stimulated by their greed, pulled in an irresponsible manner and without planning, natural resources for profit committed to sustainable livelihoods. The traditional view emphasizes an anthropocentric environmental urban development focused on the interests and welfare of human beings since man's existence, while the biocentric, shifts the axis of ethics for living beings and natural ecosystems, where we have the introduction to environmental ethics in 70's and the concept of eco-development.
\end{abstract}

Keywords: evolution, urban environmental sustainability, ethics anthropocentric, biocentric ethics, eco-development.

\section{INTRODUÇÃO}

Como se sabe, o século XIX marcou profundamente o avanço da urbanização e a carência de infra-estrutura, que resultou nas condições atuais das cidades que concentram cada vez mais, grande parte da população do planeta.

A ação antrópica, fortemente concentrada nas cidades, gerou grande impacto no ambiente construído e no meio físico em que o ser humano se inseriu. O aumento da população associado à diminuição de recursos naturais conduz as cidades a uma situação de esgotamento iminente. Esgotamento de recursos não renováveis e degradação que ocorre no solo, água, vegetação e ar, pois o ser humano retira do ambiente natural, os recursos necessários para sua sobrevivência e age como se estes fossem infinitos. 
A qualidade da vida humana está diretamente relacionada com a interferência do ser humano no ambiente construído. A natureza humanizada, através das modificações no ambiente, alcança maior expressão nos espaços ocupados pelas cidades. A partir desse cenário, pode-se tentar compreender a importância da ética no processo de evolução da sustentabilidade ambiental, haja visto que a ética envolve todas as relações da vida humana. Os problemas éticos são apresentados aos seres humanos, relativamente às atividades econômicas, sociais e ambientais. "Nas últimas décadas, crises de âmbito mundial, como fome e miséria, migração da pobreza e superpopulação, destruição ininterrupta do ambiente natural e guerras, despertaram a exigência de uma responsabilidade mais ética" (ENDERLE, 1997).

Se a humanidade não pensar e agir a partir de uma ética ambiental, enfrentará os efeitos negativos dos últimos duzentos anos de crescimento populacional e econômico que fatalmente levaram ao desequilíbrio ecológico e a degradação do meio ambiente físico e social. As ações sustentáveis precisam ser vistas como elemento essencial para o alcance da melhoria da qualidade de vida do ser humano e da preservação do ambiente natural. $O$ debate ecológico levanta questões fundamentais na maneira como a ética se posiciona perante o processo de evolução das questões ambientais. O próprio ponto de partida e a abrangência da ética enfatizam diferentes enfoques; antropocêntricos ou biocêntricos. Uns partem de que o ser humano detém um protagonista no mundo. Buscam a solução para os problemas ambientais na perspectiva do papel central do ser humano em relação à natureza. Outros defendem que o ser humano é apenas um elemento a mais no ecossistema da natureza, um elo ao lado de outros na cadeia de reprodução da vida. Por isso, o protagonista pertence à vida. Para estes a crise ecológica precisa ser equacionada numa perspectiva biocêntrica.

Desta maneira foram-se perfilando duas grandes tendências de ética ecológica que se excluem entre si. Uma que tem como ponto de partida o ser humano em sua postura ética. Defende que não existe ética sem antropocentrismo, pois somente o ser humano pode agir moralmente e tomar decisões. A outra, a postura biocêntrica, que parte do ponto de vista da ecologia como conhecimento e prática de preservação do meio ambiente. Essa tendência compreende a ética a partir do paradigma da ecologia. Esse paradigma pretende revolucionar a ética, porque supera a concentração antropocêntrica de toda ética ocidental. Apresenta-se como a única postura coerente de defesa da natureza e preservação do meio ambiente. 
De acordo com os grandes acontecimentos urbanísticos e paisagísticos, será analisada a evolução da sustentabilidade ambiental urbana e suas interfases com a ética.

\section{CONCEITO DE SUSTENTABILIDADE AMBIENTAL}

A sustentabilidade é vista como "um princípio em evolução", "um conceito infinito", "que poucos sabem o que é" e "que requer muita pesquisa adicional", manifestações de um positivismo frustrado: o desenvolvimento sustentável seria um dado objetivo que, no entanto, não se conseguiu ainda apreender. Mas, como definir algo que não existe? E que, ao existir, será, sem dúvida, uma construção social? E que, como tal, poderá também compreender diferentes conteúdos e práticas a reivindicar seu nome. Isto nos esclarece por que distintas representações e valores vêm sendo associados à noção de sustentabilidade: são discursos em disputa pela expressão mais legítima. Pois a sustentabilidade é uma noção a que se pode recorrer para tornar objetivas diferentes representações e idéias.

\section{CONCEITO DE ÉTICA}

Etimologicamente a palavra ética deriva do grego éthos que significa costume designando a doutrina do agir correto, ou seja, do agir bem e o vocábulo moral deriva do latim, mos, mores que significa costumes, hábito. A ética e a moral, originalmente têm o mesmo significado, entretanto, há uma distinção entre ambas. "Moral designa o que se faz, portanto as convenções, o habitual, a moral de todos os dias, a moral da mediania, enquanto ética indica a reflexão, se o que é habitual realmente é bom e certo" (ENDERLE, 1997). Vázquez define a ética como a "teoria ou ciência do comportamento moral do ser humano em sociedade, ou seja, é ciência de uma forma específica de comportamento humano" (2002). Em suma, a ética é a ciência da moral. Ele esclarece ainda que a moral não é considerada ciência, mas objeto de estudo da ciência; sendo, neste sentido, por ela estudada e investigada.

Lima (1999), além de esclarecer que "A ética é a exteriorização dos juízos morais (ciência da conduta)", descreve que a Ética é a filosofia que estuda a conduta do ser humano e os critérios pelos quais valoram os comportamentos e a escolha. 
"Parte da filosofia responsável pela investigação dos princípios que motivam, distorcem, disciplinam ou orientam o comportamento humano, refletindo especialmente a respeito da essência das normas, valores, prescrições e exortações presentes em qualquer realidade social". (HOUAISS 2001)

A ética varia de acordo com o estágio de desenvolvimento do ser humano e de suas relações em sociedade. Lima (1999) esclarece que ser ético "significa ter consciência dos procedimentos permitidos e proibidos dentro da sociedade, dando o exemplo de conduta positiva, zelando para que todos observem os princípios legais, desenvolvendo-se e educando-se continuamente".

\section{EVOLUÇÃO DA DA SUSTENTABILIDADE AMBIENTAL}

No final do século XVIII com a Revolução Industrial na Inglaterra, a insalubridade observada na maior parte das cidades industriais européias, demandou ações corretivas voltadas ao resgate da qualidade ambiental.

O apelo à qualificação estética de áreas da cidade, também ganhou importância tanto quanto a busca da higienização. Neste período, na Inglaterra o parque surge como fato urbano de relevância, atingindo seu pleno desenvolvimento apenas cem anos depois. O Parque Urbano passou a responder pela demanda de equipamentos para as atividades de recreação e lazer decorrentes da intensificação da expansão urbana da cidade industrial. Dois processos distintos marcaram a criação dos primeiros parques urbanos na Inglaterra: a absorção dos grandes espaços livres representados pelos jardins dos palácios da Corte, que foram abertos ao público e incorporados à estrutura urbana e os empreendimentos imobiliários promovidos pela iniciativa privada.

O movimento dos Parques Americanos liderado por Frederick Law Olmsted se coloca contra os males das cidades industrializadas e surgem os grandes jardins contemplativos, os parques de paisagem, os parkways (parques lineares) e os parques de vizinhança americana, como o Central Park em Nova lorque, 1863. Com base nestas preocupações, Olmsted realiza em Boston a primeira experiência de organização de um sistema de parques que considera o conjunto da cidade. Na concepção desse sistema de parques, conhecido como "Emerald Necklace", pelo fato de se tratar de um 
conjunto de espaços interligados, Olmsted teve como preocupação, além da questão do lazer, a questão do saneamento do ambiente urbano e da sua recuperação.

A implantação de parques urbanos nas cidades tem seu caráter de punho ambiental, mas o principal argumento é o bem estar da população; ou seja, os interesses sociais e ambientais do ser humano; ele que irá usufluir do espaço "construído". De acordo com Taylor, "nossos deveres com o mundo natural derivam, no fundo, de nossos deveres para com os seres humanos. É porque temos de respeitar os direitos humanos de cada um, ou porque temos de proteger e fomentar o bem-estar de humanos que devemos estabelecer certos limites em nosso modo de tratar o ambiente natural terrestre e seus habitantes não-humanos." Em outras palavras, a ética ambiental antropocêntrica dominante desde o século XVI, surge em contraste com a ética teocêntrica e teológica da Idade Média, desconsidera o Deus supremo como centro do universo e leva o homem à condição de espécie superior pela razão, priorizando os interesses econômicos, científicos e estéticos acima de tudo. Por essa razão, sua lógica é instrumental, e seu argumento dos deveres para com o ecossistema é indireto.

O filósofo alemão do século XIX, Emmanurl kant, defende que as perspectivas antropocêntricas estabelecem os deveres morais positivos e negativos tendo em vista o bem dos seres humanos, colocado no centro e acima do bem de qualquer outro ser vivo. Por isso a designação "ética antropocêntrica". Essa ética, ao engrandecer a natureza humana, afirmando que os interesses e propósitos humanos estão acima de quaisquer interesses ou fins de quaisquer indivíduos de outras espécies nesse planeta, coloca em segundo plano, para não dizer, em último lugar, os interesses de todas as demais espécies de vida. Estamos vivendo nesse momento a ameaça de destruição da vida, que tal ética ensejou.

A tese do antropocentrismo excludente, típica da filosofia moderna inaugurada por Descartes, vigorou até metade do século XX, quando começaram a tomar força as éticas ecológicas ou ambientais. A ética ambiental antropocêntrica fomentou a maioria das ações ambientalistas levadas a efeito ao redor do planeta nos últimos 40 anos. Seu fracasso pode ser constatado pela devastação ambiental em curso acelerado. Para evitar cometer erros antigos, é preciso finalizar a crítica ao caráter antropocêntrico da proposta ética tradicional, contrapondo seu fundamento ao princípio que estrutura a ética ambiental biocêntrica. Ao forjar o modelo ético biocêntrico, agentes morais humanos são colocados num plano horizontal relativamente a todas as espécies de vida, nem acima, nem abaixo, ainda que no centro. 
As preocupações da humanidade com a qualidade ambiental no processo de desenvolvimento se fortaleceram no período que sucedeu a Segunda Guerra Mundial (1939-1945). A destruição das cidades influenciou um novo modo de pensar o desenho urbano; como a redução da destruição de solos, o aumento das áreas permeáveis, a redução do custo de infra-estrutura urbanística, a redução da poluição e a descentralização.

Surge neste período pós-guerra, a Ética da Terra (1949), por Aldo Leopold, onde serviu de inspiração para os princípios ecocêntricos da Ética Ambiental Contemporânea: A ética da Terra é uma abordagem ética holística, derivada de mais de um paradigma biológico que de uma tradição filosófica. Leopold definiu uma ética a partir desse ponto de partida biológico como uma limitação da liberdade de ação na luta pela vida. Assim, a ética ecológica, amplia os limites da comunidade para incluir solos, águas, plantas e animais, ou a própria Terra. Para Leopold "Uma coisa é correta quando tende a preservar a integridade, a estabilidade e a beleza da comunidade biótica. E é errada quando tende a ter outro resultado".

Na década de 60, a deterioração ambiental e sua relação com o estilo de crescimento econômico já eram objeto de estudo e preocupação internacional. Nesse sentido, podemos citar como exemplos: o livro Primavera Silenciosa, de Rachel Carson, lançado em 1962, que trata do uso e dos efeitos dos produtos químicos sobre os recursos ambientais, o livro Design With Nature, de lan Mcharg, em 1969, sobre o planejamento urbano com bases ecológicas e Albert Shweitzer, que ganhou o Prêmio Nobel da Paz ao popularizar a ética ambiental.

A Ética Ambiental surge em meio a esta visão ecocêntrica de Leopold, como uma nova relação de consciência entre o ser humano e o ambiente natural: o ser humano faz parte do ambiente natural e não é o seu dono, não a tem para servi-lo, mas para que ele sobreviva em harmonia com os demais seres. Nesta nova concepção, o ser humano passa a se preocupar com suas ações e, como conseqüência, passa a praticar ações coerentes com o ambiente natural. Deve agir contra os desastres cotidianos nas cidades, como o desmatamento, a ocupação de encostas e fundos de vale, o esgoto e lixões a céu aberto, a poluição das águas de nascentes, a poluição das praias, a venda de animais silvestres em feiras livres e o comércio de plantas nativas em extinção, entre outros. 
A partir da década de 70, formam-se grupos de discussão cujo enfoque principal era a preocupação ambiental e sua importante influência para o desenvolvimento mundial. O Clube de Roma, um dos primeiros grupos a se concretizar, nasceu em 1968, congregando cientistas, economistas e altos funcionários governamentais, com a finalidade de analisar os problemas ambientais, sob uma perspectiva ecológica de Sistema Global.

O arcabouço teórico do pensamento do Clube de Roma reside na idéia de que o planeta é um sistema finito de recursos, submetido às pressões do crescimento exponencial da população e da produção econômica. As suas conclusões apontavam o horizonte do colapso do sistema e as suas propostas se organizavam em torno da noção de um gerenciamento global da demografia e da economia, a fim de alcançar um estado de equilíbrio dinâmico. Severas medidas de controle da natalidade e mudanças radicais nos modelos produtivos eram as recomendações centrais da nova escola de pensamento ecológico.

A publicação em 1972 do relatório Os limites do Crescimento (Meadows et al., 1972) pelo Clube de Roma denunciava o crescente consumo mundial que ocasionaria um colapso do ecossistema global. Realizado pela equipe do Professor Meadows, do MIT - Massachusetts Institute of Technology, o relatório atentava para a preocupação com as principais tendências do ecossistema mundial: industrialização acelerada, forte crescimento populacional, insuficiência crescente da produção de alimentos, esgotamento dos recursos naturais não renováveis e degradação irreversível do ambiente natural.

As questões relativas à qualidade ambiental se fortaleceram com a Reunião de Estocolmo de 1972 na Suécia, onde foram discutidos os potenciais efeitos nocivos das mudanças climáticas e os estilos de desenvolvimento sócio-econômico dos países em relação ao ambiente natural. Tratou-se das questões ambientais e da qualidade de vida e buscaram alternativas para o uso dos recursos naturais com o objetivo de satisfazer as necessidades globais de subsistência da população, como moradia, educação, saúde e alimentação. Ao final, foi criado o Programa das nações Unidas para o Meio Ambiente (PNUMA).

Surge em meio às discussões ambientais da década de 70 , uma nova visão de ética ambiental por Paul Taylor; a Ética da Vida ou biocentrismo. Ela surge como uma das tendências mais recentes no movimento ecológico. O biocentrismo propõe que os di- 
reitos naturais deveriam ser estendidos a todos os elementos da natureza, e que uma postura ética radical deveria ser tomada antes que todos os seres humanos, e mesmo seres inanimados, modifiquem completamente a relação entre a humanidade e a natureza. Roderick Nash analisa o biocentrismo em seu livro "Os direitos da natureza", e o interpreta como uma conseqüência do liberalismo.

Taylor, com sua ética biocêntrica, sugere que seja levado em consideração o valor inerente à vida de cada indivíduo, não significando isso que em hipótese alguma uma vida não possa ser eliminada. Mas a razão pela qual uma vida pode ser exterminada deve ser uma razão ética, descartando-se a hipótese de que interesses comerciais, estéticos, científicos ou de qualquer natureza antropocêntrica possam servir como pretexto para que tiremos a vida dos outros. Isso vale para humanos, animais não humanos e ecossistemas naturais. Por isso a designação biocêntrica para tal proposta ética.

Por outro lado, a natureza não dá lições de ética, pois nela não há deveres, apenas leis. Seus eventos, portanto, não podem nos guiar moralmente. Esse é o ponto da ética biocêntrica que a distingue da ética ecocêntrica oriunda da ecologia profunda de Leopold (The Sand County Almanac, 1949), Baird Callicott, Albert Schweizer.

A ética biocêntrica de Paul W. Taylor, apresentada em seu livro, Respect for Nature, e o conceito de ecodesenvolvimento são concebidos, ambos na década de 70 , como um questionamento à ação devastadora dos ecossistemas naturais. Após a grande polêmica gerada na primeira Conferência das Nações Unidas sobre o Meio Ambiente, em Estocolmo (1972), entre aqueles que defendiam o desenvolvimento a qualquer preço, mesmo pondo em risco a própria natureza e os partidários das questões ambientais foi proposto o termo ecodesenvolvimento por Maurice Strong e, em seguida, ampliado pelo economista Ignacy Sachs, que, além da preocupação com o meio ambiente, incorporou as devidas atenções às questões sociais, econômicas, culturais, de gestão participativa e ética.

Para Sachs, ecodesenvolvimento é um "desenvolvimento endógeno e, dependente de suas próprias forças, submetidas à lógica das necessidades do conjunto da população, consciente de sua dimensão ecológica e busca estabelecer uma relação de harmonia entre o ser humano e o ambiente natural".

Os princípios básicos do ecodesenvolvimento foram formulados por Ignacy Sachs dentro de uma nova proposta de desenvolvimento sustentável, tendo como pressu- 
posto a existência de cinco dimensões, que propõe ações que explicitam a necessidade de tornar compatíveis a melhoria nos níveis de qualidade de vida e a preservação ambiental. São elas as cinco dimensões:

a. Econômica: aumentar a lucratividade e crescimento por meio do uso mais eficiente de recursos, incluindo mão-de-obra, materiais, água e energia;

b. Ambiental: evitar efeitos perigosos e potencialmente irreversíveis no ambiente por meio de uso cuidadoso de recursos naturais, minimização de resíduos, e proteção e, quando possível, melhoria do ambiente;

c. Social: responder às necessidades de pessoas e grupos sociais envolvidos em qualquer estágio do processo de construção (do planejamento a demolição), provendo alta satisfação do cliente e do usuário, e trabalhando estreitamente com clientes, fornecedores, funcionários e comunidades locais;

d. Geográfica: necessidade de se buscar uma configuração rural-urbana mais equilibrada e de se estabelecer uma rede de reservas da biosfera para proteger a diversidade biológica e, ao mesmo tempo, ajudar a população local a viver melhor;

e. Cultural: talvez, constitua o critério mais difícil de ser concretizado, na medida em que implica que o processo de modernização deva ter raízes endógenas, buscando a mudança em sintonia com a continuidade cultural vigente em contextos específicos.

Na proposta de ecodesenvolvimento, a educação ambiental contribui para a compreensão fundamental da relação e interação da humanidade com todo o ambiente natural e fomenta uma ética ambiental a respeito do equilíbrio ecológico e da qualidade de vida, despertando nos indivíduos e nos grupos sociais organizados o desejo de participar da construção de sua cidadania.

\section{METABOLISMO DAS CIDADES}

O conceito de metabolismo das cidades, segundo o desenvolvimento sustentável, consiste no balanço da entrada de recursos naturais e saída de resíduos. O metabolismo urbano explica a dinâmica de uma cidade e a relação com seus integrantes: moradores, indústrias, veículos, lixo e outros que constituem o ambiente construído. 
Na visão de Tickell (2001) "as cidades são como organismos que absorvem recursos e emitem resíduos". E é sob este prisma que se considera o metabolismo urbano das cidades, como forma de compreender o impacto de seus processos no ambiente natural.

A cidade precisa de insumos para manter sua população e seus processos produtivos: a energia em suas diversas formas, tais como elétrica, solar, eólica, entre outras, os alimentos, a água e a matéria-prima. A produção ou extração de cada um desses insumos impacta de forma mais ou menos intensa a área onde ocorre. A poluição do ar, os efluentes líquidos, os resíduos sólidos e os produtos químicos são resíduos que precisam de uma área capaz de assimilá-los. Essas áreas sofrem sérios impactos ambientais.

Essas áreas impactadas são conceituadas como Pegada Ecológica por Wackernagel e Rees (1996) que se basearam no conceito de "capacidade de carga", a qual permite calcular a área de terreno produtiva necessária para sustentar o estilo de vida do ser humano.

Na cidade, a Pegada Ecológica é vista como a área impactada no processo de produção de seus insumos - necessária à vida do ser humano - somada ainda à área necessária para a disposição e a assimilação de seus resíduos, mas seu conceito pode ser utilizado em diversas escalas, da individual à planetária. Sobre esta questão, a explicação dada pela equipe da organização Urban Ecology Austrália é a seguinte:

A pegada ecológica é uma ferramenta muito simples para nos dizer quanta natureza temos, quanta usamos. Nós precisamos olhar para a pegada ecológica para olhar para a saúde dos serviços ecossistêmicos que suportam nossa economia. Nós podemos fazê-lo no nível global, no nível nacional, no nível municipal ou até no nível individual (GIRARDET, 1997).

O metabolismo urbano, com uma representação ecossistêmica das cidades, composta por movimentos interativos de circulação, troca e transformação de recursos em trânsito defini-se, diante do discurso sobre a sustentabilidade das cidades, pelo recurso à metáfora biológica da "resiliência", que procura descrever a capacidade adaptativa dos "ecossistemas urbanos" para superarem a sua condição de vulnerabilidade ante a choques externos (Godard, 1996, p.33). Neste tipo de representação, a in- 
sustentabilidade expressaria a incapacidade de reprodução adaptativa das estruturas urbanas diante de rupturas nas condições materiais requeridas para tal reprodução. A idéia de metabolismo urbano aponta para um modelo de equilíbrio a ser obtido pelo ajustamento apropriado dos fluxos e estoques de matéria e energia.

\section{METABOLISMO LINEAR}

Com estas considerações pode-se analisar o metabolismo das cidades do século XX como um metabolismo linear, no qual são recebidos insumos e emitidos dejetos quase que indiscriminadamente. Pode-se então representar esse metabolismo graficamente tal como o fez Girardet (Figura 1):
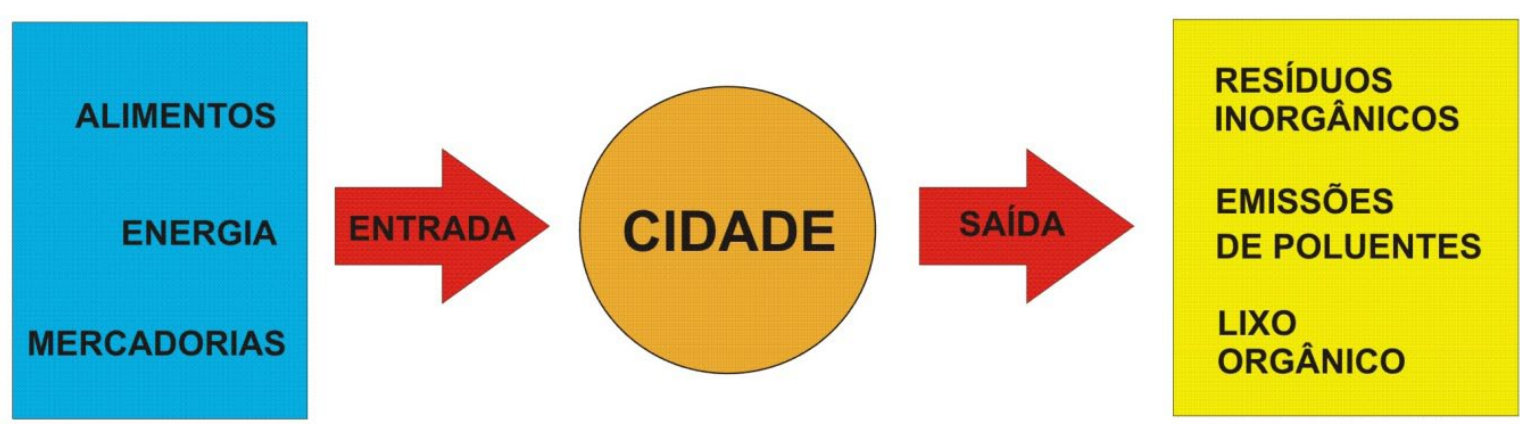

Figura 1: Modelo de metabolismo linear das cidades. Fonte: Adaptação elaborada pela autora a partir de GIRARDET, 1997.

\section{METABOLISMO CIRCULAR}

Girardet (1997) propõe um metabolismo circular em que a entrada de insumos feita linearmente no modelo anterior possa ser diminuída por meio de controle de entrada de energia e maximização de reciclagem, conseqüentemente reduzindo a produção de resíduos (Figura 2). 


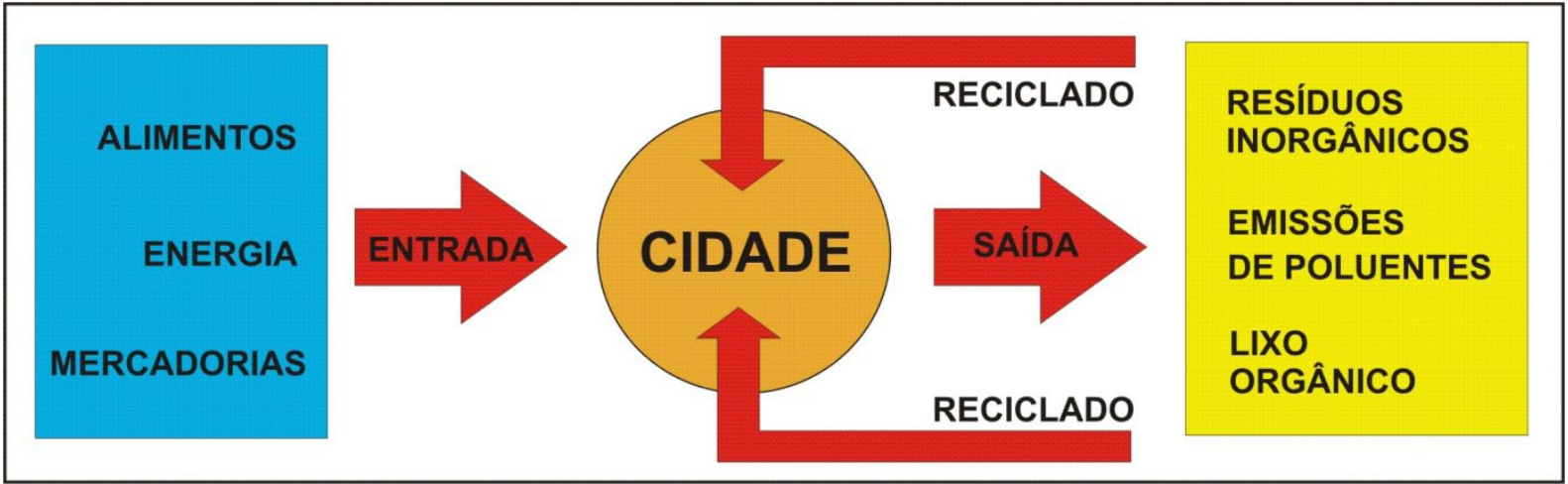

Figura 2: Modelo de metabolismo circular das cidades. Fonte: Adaptação elaborada pela autora a partir de GIRARDET, 1997.

Analisando o metabolismo circular temos no processo de entrada os alimentos, a energia e as mercadorias. A partir do consumo destes recursos pela cidade teremos as conseqüências negativas no processo de saída dos resíduos e a necessidade de propor diferentes soluções para o consumo sustentável dos recursos.

Em termos urbanísticos, o próprio desenho das cidades pode ser pensado para meIhorar as condições de conforto e saúde e as qualidades ambientais, como por exemplo, reduzindo gastos com climatização e gerando caminhos de ventos adequados para manter um equilíbrio climático.

A reciclagem de produtos e de embalagens pode tornar menor a quantidade de matéria-prima necessária para a indústria, diminuir a mineração e a extração de materiais da natureza, diminuir a quantidade de energia necessária e diminuir ainda a poluição gerada no momento da produção.

A poluição do ar nas cidades é produzida na maior parte pelos meios de transporte movidos a combustíveis fósseis que precisam ser substituídos. Os veículos que venham adotar tecnologias renováveis e menos poluentes trarão melhores condições e eficiência para os transportes e irão colaborar para alterar a entrada no modelo de metabolismo circular contribuindo para um desenvolvimento mais sustentável.

A poluição da água, por vezes, é decorrente do descaso com relação aos efluentes. Estes precisam ser recolhidos e tratados de maneira apropriada, antes de serem devolvidos aos corpos de água. Outra forma de contaminação é a transferência da poluição do ar e do solo para a água. 
Os solos urbanos também passam pelo problema da poluição ao se tornarem brownfields (campos marrons). Termo que surgiu em 1992, nos EUA, durante uma investigação de campo conduzida pela Northeast Midwest Congressional Coalition, grupo de representantes que estudam os problemas ambientais dos estados americanos.

Sánchez (2001) define brownfields como edifícios ou terrenos previamente usados para fins industriais ou para determinados fins comerciais, que estão desocupados e freqüentemente contaminados por baixas concentrações de lixo tóxico ou poluição, e que possui o potencial para ser reutilizado desde que seja limpo. Terrenos que apresentam altas concentrações de lixo tóxico não podem ser enquadrados na classificação de brownfields.

Não se pode esquecer outra importante fonte de contaminação dos solos e dos lençóis freáticos, que são os dejetos, seja na forma dos esgotos - que muitas vezes correm ao ar livre ou são acumulados em fossas construídas de forma inadequada ou em terrenos que não as comportam - ou dos lixões que ocorrem em terrenos sem preparo. Os lixões são áreas de disposição final de resíduos sólidos que não contam com preparação anterior do solo, e nem com sistema de tratamento do chorume, efluente líquido que escorre do lixo, penetra na terra e contamina solo e lençóis freáticos. Moscas, pássaros e ratos circulam a céu aberto, enquanto crianças, adolescentes e adultos catam comida e materiais recicláveis para vender. Já o aterro sanitário é constituído por um sistema de drenagem de efluentes líquidos percolados (chorume) acima de uma camada impermeável de polietileno de alta densidade - PEAD, sobre uma camada de solo compactado para evitar o vazamento de material líquido para o solo, evitando assim a contaminação de lençóis freáticos. O chorume deve ser tratado e/ou recirculado causando assim uma menor poluição ao meio ambiente.

A idéia do metabolismo circular prevê que parte do resíduo que deixa as cidades no metabolismo linear seja reaproveitada, servindo-lhe de insumo, ao mesmo tempo em que compõe uma componente cíclica do sistema. A redução dos resíduos e da poluição da cidade é proporcional à redução de consumo de recursos naturais pelo ser humano.

A produção de energia, alimentos e mercadorias pela cidade causam um impacto negativo no ambiente natural. Os dejetos produzidos em grande escala nas áreas urbanas são despejados na natureza, na maioria das vezes sem cuidados, aumentando 
as áreas necessárias para sua disposição final e, conseqüentemente, aumentando as Pegadas Ecológicas das cidades.

Para obter um metabolismo circular no funcionamento das cidades são essenciais atitudes por parte do governo, dos empreendedores e do cidadão na busca de tecnologias que reduzam os impactos das atividades do ser humano, como a produção de insumos de forma mais limpa e a disposição de resíduos de forma correta: como a neutralização do lixo tóxico e o tratamento e reaproveitamento dos resíduos.

O relatório Brundtland de 1987 realizado pela Organização das nações Unidas e presidido por Gro Harlem Brundtland, ex-primeira ministra da Noruega, líder em desenvolvimento sustentável e saúde pública, discute intensamente a proteção ambiental e o conceito de desenvolvimento sustentável (Figura 3), o qual tem como base conceitual três pilares: a atividade econômica, o meio ambiente e o bem estar da sociedade.

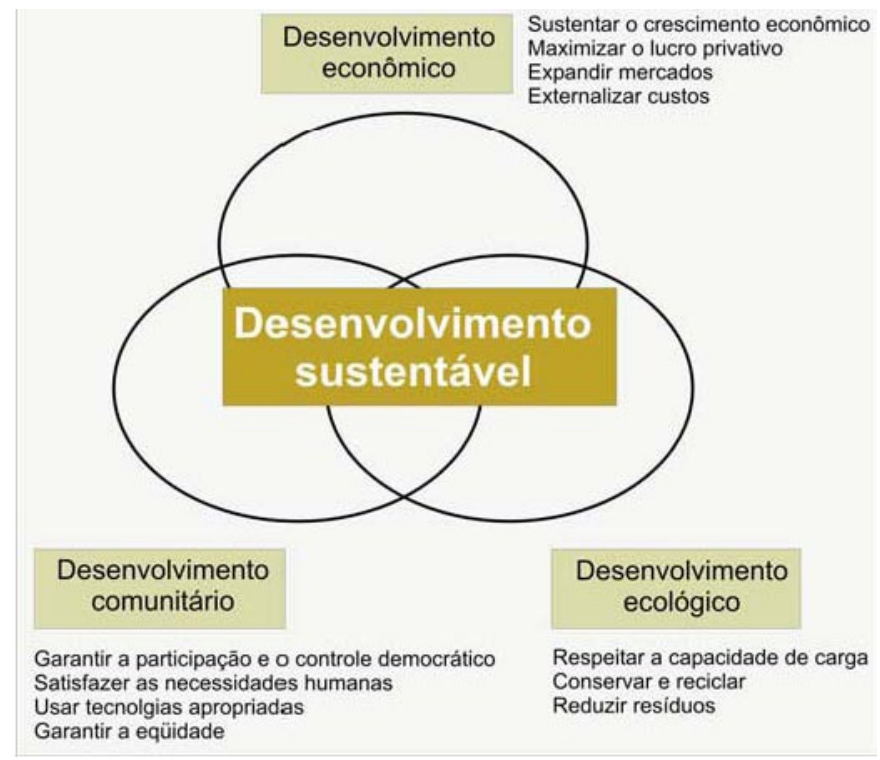

Figura 3: Conceito de desenvolvimento sustentável. Fonte: Adaptação pela autora do CIB (1996).

O desenvolvimento sustentável busca hoje uma interação entre o desenvolvimento econômico, a qualidade ambiental e a satisfação das necessidades do ser humano. É um processo de modificações no qual está previsto que a exploração de recursos, a direção dos investimentos, a orientação do desenvolvimento tecnológico e as mudanças institucionais deverão ser feitas consistentemente para atender as necessidades do presente sem comprometer a possibilidade das gerações futuras atenderem às suas próprias necessidades (BRUNDTLAND, 1987). Para que isso se torne realidade 
é necessária uma série de ações conjuntas e cooperadas entre o poder público e a iniciativa privada, além de um consenso internacional. Há também os movimentos sociais formados principalmente por ONG's, que defendem melhores condições de vida associadas à preservação do ambiente natural e a uma condução da economia adequada a tais exigências.

"O desenvolvimento sustentável pretende combater a miséria humana sem repudiar a natureza ou desconsiderar as especificidades locais. Introduzir o objetivo global de um crescimento econômico e social duradouro, e que não dilapide o patrimônio natural".

(AGENDA 21, 1996)

A CNUMAD - Conferência das Nações Unidas sobre Meio Ambiente e Desenvolvimento em 1992 no Brasil, contou com a participação dos principais líderes de mais de cem nações. As pesquisas científicas realizadas até aquele ano não deixavam mais nenhuma margem de dúvida quanto ao perigoso caminho traçado pelo ser humano, em sua insaciável busca por padrões de vida incompatíveis com a capacidade de suporte do planeta. Esta conferência foi baseada em três princípios: análise da totalidade do ciclo de vida dos materiais, desenvolvimento do uso de matérias-primas e energias renováveis e a reciclagem de resíduos.

A questão ambiental embasada nesses preceitos acima propiciou a celebração de diversos acordos internacionais, com destaque para a Agenda 21, a qual foi assinada em 1992 por 178 países. É uma Agenda de Desenvolvimento Sustentável onde predomina uma proposta que rompe com o planejamento com enfoque econômico e destaca o ambiente natural. Ela discute a essência do que é desenvolvimento sustentável, o processo através do qual ele pode ser alcançado e as ferramentas de gerenciamento necessárias para alcançá-lo. A Agenda 21 não é restrita às questões ligadas à preservação e conservação da natureza, mas sim, às questões estratégicas ligadas: à geração de emprego e de renda, à diminuição das disparidades regionais e interpessoais de renda, às mudanças nos padrões de produção e consumo, à construção de cidades sustentáveis e à adoção de novos modelos e instrumentos de gestão (HADDAD, 2002).

É importante ressaltar que, apesar das críticas a que tem sido sujeito, o conceito de desenvolvimento sustentável representa um importante avanço, na medida em que a Agenda 21, como plano abrangente de ação para o desenvolvimento sustentável no 
século XXI, considera a complexa relação entre o desenvolvimento e o meio ambiente numa variedade de áreas, destacando a sua pluralidade, diversidade, multiplicidade e heterogeneidade.

\section{CONSIDERAÇÕES FINAIS}

A natureza, como já foi dito, submeteu-se à intervenção técnica dos homens, mesmo sendo ela independente dos desejos e das opiniões humanas. O homem deveria deixá-la cumprir seu objetivo, sob pena de transformá-la em bem fictício, carente de seu verdadeiro valor. Por essa razão, é importante adotar modos de vida e caminhos de desenvolvimento que respeitem e funcionem dentro dos limites da natureza.

A ética ambiental, porém, não prevê a mudança de um paradigma. Ela simplesmente ensina que, para continuar vivendo com conforto e segurança ambiental, é preciso adotar uma postura sustentável, sem, no entanto, ser necessário romper com o paradigma antropocêntrico e adotar uma ética biocêntrica. A mesma vem sendo aplicada, desde o momento em que se falou pela primeira vez em desenvolvimento sustentável, já na década de 70, com o Relatório das Nações Unidas sobre Meio Ambiente.

O homem não deve ocupar o centro da política ambiental, ainda que comumente ele busque um lugar prioritário. Haverá casos em que para se conservar a vida humana ou para colocar em prática a harmonia com a natureza será preciso conservar a vida dos animais e das plantas em áreas declaradas inacessíveis ao próprio homem.

A ameaça ao ambiente é uma questão eminentemente ética, depende de uma alteração de conduta do ser humano; e para haver essa alteração, o agir com dever e em colaboração com os outros seres é a primeira exigência na tentativa de reaver o equilíbrio do planeta.

\section{RESULTADOS}

A natureza tem seu modo de ser, suas leis e seus comportamentos. Assim, não podemos pensar uma ética para o homem e outra para a natureza. A interdependência do homem e da natureza exige uma ética que não sobreponha o racional ao irracional (ou segundo Darwin - o mais inteligente sobre o menos inteligente), mas uma igualdade naquilo que é essencial para 
ambos - a sobrevivência. Devemos ter, então, uma Ética Ecológica ou Integradora (Albert Schweitzer), ou seja, uma ética em que todos os seres vivos são importantes e inteiramente necessários. Assim, o homem é conduzido a dar a todo desejo de vida a mesma reverência pela vida que dá ao seu próprio desejo de viver.

Trata-se de reconhecer que, embora em escalas diferentes, ambos, homem e natureza, possuem valores complementares porque as interações biológicas estão interligadas entre si, de tal forma, que desequilíbrios afetam ambas as partes. A destruição de florestas, por exemplo, não afeta só os vegetais e animais que ali interagem, mas o próprio homem e seu meio ambiente.

Faz-se importante estudar, mesmo que de forma sucinta, a ética, para se tentar encontrar a melhor maneira de resolver os problemas sociais e ambientais. Sendo a ética uma espécie de instinto da comunidade em sua realização, talvez a busca de novos caminhos e novas formas de agir ético traga boas soluções para o caos atual.

\section{BIBLIOGRAFIA}

ACSERALD, H. Discursos da sustentabilidade urbana. Revista Brasileira de Estudos Urbanos e Regionais, Campinas, n¹, maio. 1999.

ACSELRAD, H. Sustainability and Territory. In: Internacional Seminar on "Sustainability as a Concept for Social Sciences”. Frankfurt: ISOE/Unesco, 1996.

BRUNDTLAND, G. Nosso futuro comum.São Paulo: Editora Fundação Getúlio Vargas, 1987. FRANCO, Maria de Assunção Ribeiro. Planejamento Ambiental para a Cidade sustentável. São Paulo, Annablume, 2000, 296p.

GIRARDET, Herbert. "Sustainble Cities. A Contradiction in Terms?" in AD Architectural Design The Architecture of Ecology, London, 1997.

JONAS, Hans. Das Prinzip Verantwortung. Versuch einer Ethik für die technologische Zivilisation. Frankfurt am Main: Insel Verlag, 1979.

LIMA, Alex Oliveira Rodrigues de. Ética global: legislação profissional no terceiro milênio. São Paulo: Iglu, 1999. 
MACCLOSKEY,apud CAPELLA, Vicente Bellver. Ecologia: de las razones a los derechos. Granada: Comares, 1994.

MACHADO, Paulo Affonso Leme. Direito Ambiental Brasileiro. 14. ed. São Paulo: Malheiros, 2006.

MILARÉ, Édis. Processo Coletivo Ambiental. In: BENJAMIN, Antônio Herman (Coord.). Dano Ambiental: Reparação, prevenção e repressão. São Paulo: Revista dos Tribunais, 1993.

NALINI, José Renato. Ética ambiental. Campinas: Millennium, 2001. p. XXII.

NASH, Roderick. The Rights of Nature: A History of Environmental Ethics, 1989.

SÁNCHEZ VÁZQUEZ, A. Ética. 23. ed. Rio de Janeiro: Civilização Brasileira, 2002.

TAYLOR, Paul W. Respect for Nature: Studies in Moral, Political, and Legal Philosophy. Princeton NJ: Princeton University Press, 1986.

TAYLOR, Paul W. The Ethics of Respect for Nature. In: ZIMMERMANN, Michael; CALLICOTT, J. Baird; SESSIONS, George; WARREN, Karen J; CLARK, John (Eds.) Environmental Philosophy: From Animal Rights to Radical Ecology. Upper Saddle River NJ: Prentice Hall, 1998.

THOMAS, K. O Homem e o Mundo Natural. Companhia das Letras, SP, 1983.

TICKELL, Crispin. "Introdução". In: ROGERS, Richard. Cidades para um pequeno planeta. Barcelona, Gustavo Gili, 2001.

VÁZQUEZ, Adolfo Sánchez. Ética. Tradução: João Dell'Anna. 23. ed. Rio de Janeiro: Civilização Brasileira, 2002. 